DOI: $10.14451 / 1.180 .39$

\title{
ОТЕЧЕСТВЕННЫЙ И МИРОВОЙ ОПЫТ В РАЗВИТИИ РЫНКА СЫРОВ И СЫРНЫХ ПРОДУКТОВ
}

\author{
(C) 2019 Жукова Наталья Викторовна \\ кандидат экономических наук, проректор по учебно-методической работе \\ Московский государственный университет технологий и управления \\ имени К.Г. Разумовского (ПКУ), Россия, Москва \\ (c) 2019 Сурай Наталья Михайловна \\ кандидат технических наук, доцент кафедры экономики и управления \\ Московский государственный университет технологий и управления \\ имени К.Г. Разумовского (ПКУ), Россия, Москва \\ E-mail: natalya.mixajlovna.1979@mail.ru \\ (c) 2019 Майоров Александр Альбертович \\ доктор технических наук, профессор \\ Сибирский Научно-исследовательский институт сыроделия \\ Федерального Алтайского научного центра агробиотехнологий, Россия, Барнаул
}

(c) 2019 Кудинов Богдан Дмитриевич магистрант

Алтайский государственный аграрный университет, Россия, Барнаул

E-mail: kudinov_bogdan@mail.ru

(c) 2019 Айдинов Халин Тохтарович

кандидат экономических наук, профессор, профессор кафедры экономики и управления

Московский государственный университет технологий и управления имени К.Г. Разумовского (ПКУ), Россия, Москва

\section{(c) 2019 Кудинова Маргарита Геннадьевна}

кандидат экономических наук, доцент, зав. кафедрой «Финансы, бухгалтерский учет и аудит»

Алтайский государственный аграрный университет, Россия, Барнаул

E-mail: kudinova_margarita@mail.ru

В данной статье проведен анализ отечественного и мирового опыта в развитии рынка сыров и сырных продуктов.

Ключевые слова: молоко, сельскохозяйственные организации, личные подсобные хозяйства, фермерские хозяйства, молочная промышленность, молочные предприятия, качество молока, объем производства молока.

Для России рынок сыров является одним из наиболее важных стратегических продовольственных рынков. Сыр составляет 30\% молочного российского рынка в стоимостном выражении. Обеспечение продовольственной безопасности России требует увеличения национального производства молока и молочных продуктов. После введения Россией продовольственного эмбарго в сегменте молочной продукции сохраняется значительная зависимость от импорта. Согласно данным исследования «Рынок сыра в России: исследование и прогноз до 2023 года», подготовленного маркетинговым агентством ROIF Expert, в 2019 году объем производства сыра на рынке показал рост 2,5\% что, свидетельствует о поступательном развитии рынка сыра. В настоящее время в мире насчитывается более 700 видов сыра $[1,2,14]$.

На российском рынке сыров можно отметить следующие проблемы:

- доля фальсификата на рынке сыра и сырной продукции в России составляет 20-30\%;

- недостаточный технологический уровень производств;

- деятельность недобросовестных производителей, включающих немолочные жиры в 
рецептуру продуктов, далёкое от норм качество сыра;

- рост производства «сырных продуктов» как результат смещения основного потребления в самый низкий ценовой сегмент;

- сложности с привлечением инвестиций в сыродельную сферу из-за больших сроков окупаемости проектов и дефицита сырья;

- усиление конкуренции с импортёрами, в частности с белорусскими компаниями, а также Аргентиной, Уругваем, Сербией и Украиной;

- рост цен на продукцию, превышающий инфляцию (за 5 лет средняя цена прибавила около $70 \%)$;

- риск перепроизводства в случае реализации заявленных проектов по расширению мощностей ключевых игроков;

- усиление конкуренции, что отрицательно сказывается на позициях небольших региональных игроков, провоцирует консолидацию рынка [3].

Переработка молока позволяет создать продукт с высокой добавленной стоимостью. Лидером среди молочных продуктов является сыр.
Для производства одного килограмма сыра необходимо 7-10 литров молока. Кроме того, многие сорта сыра относятся к премиальным продуктам: их производство, с учетом срока созревания, требует нескольких лет. Страны, в которых производятся такие сыры, строго подходят к соблюдению законодательства о контроле географического происхождения продукции.

Молочная отрасль США представлена мегафермами, высокими надоями и лидирующими показатели по потреблению молочных продуктов.Средний надой на одну корову составляет 10159 кг. Наибольший объем производства молока в США производится в Калифорнии, Висконсине, Нью-Йорке, Айдахо и Пенсильвании. По данным USDA, в 2018 году поголовье коров в США составляло 9,37 млн. голов, наибольшее число животных насчитывается в Калифорнии 1,8 млн. голов (табл. 1) [4].

Мировое производство сыров с 2015 года по 2018 год увеличилось на 9,5\% [5].

В структуре мирового производства сыра в 2018 году более половины приходилось на страны Европейского союза. Треть выпускали пред-

\section{Таблица 1. Объемы производства молока и численность дойного стада}

\begin{tabular}{|c|c|c|c|c|c|c|c|}
\hline \multirow{2}{*}{ Страны } & \multicolumn{3}{|c|}{$\begin{array}{c}\text { Объем производства коровьего молока, } \\
\text { млн.тонн }\end{array}$} & \multicolumn{4}{|c|}{ Поголовье дойного стада, млн.гол. } \\
\hline & 2016 г. & 2017 г. & 2018 г. & $\begin{array}{c}\text { на } \\
01.01 .2016 \text { г. }\end{array}$ & $\begin{array}{c}\text { на } \\
01.01 .2017 \text { г. }\end{array}$ & 01.01.2018 г. & 01.01.2019 г. \\
\hline в мире & 817 & 838 & 876 & 1250 & 1280 & 1300 & 1300 \\
\hline Индия & 66 & 83,6 & 84 & 53,5 & 54,5 & 55 & 56 \\
\hline EC-28 & 163,9 & 165,45 & 165,67 & 23,6 & 23,5 & 23,5 & - \\
\hline США & 96,4 & 97,8 & 98,8 & 8,72 & 9,38 & 9,37 & - \\
\hline Россия & 30,8 & 31,2 & 31,6 & 8,32 & 8,26 & 8,2 & 7,9 \\
\hline
\end{tabular}

Таблица 2. Динамика производства сыров в мире и в странах-лидерах

\begin{tabular}{|l|c|c|c|c|c|}
\hline \multicolumn{1}{|c|}{ Показатели } & 2015 г. & 2016 г. & 2017 г. & 2018 г. & $\begin{array}{c}2019 \text { г. } \\
\text { (прогноз) }\end{array}$ \\
\hline Производство сыров в мире, млн.m. & 20,1 & 20,5 & 21,1 & 22 & 24 \\
\hline $\begin{array}{l}\text { Производство сыров в ЕС-28, тыс.т. } \\
\text { в том числе: }\end{array}$ & 10271 & 10660 & 10782 & 11000 & 12240 \\
\hline - Италия, тыс.т. & 984 & 990 & 990 & 1000 & 1050 \\
\hline Производство сыров в США, тыс.т. & 5668 & 6355 & 6541 & 7260 & 7680 \\
\hline Производство сыров в Бразилии, тыс.т. & 754 & 745 & 800 & 836 & 840 \\
\hline Производство сыров в РФ, тыс.т. & 453 & 459 & 461 & 472,6 & 500 \\
\hline Производство сырных продуктов в РФ, тыс.т. & 147,9 & 159,1 & 184 & 193,5 & 200 \\
\hline $\begin{array}{l}\text { Производство сыров и сырных продуктов в РФ, } \\
\text { тыс.т. }\end{array}$ & 589 & 605 & 616 & 666,1 & 700 \\
\hline
\end{tabular}


приятия США. Далее следуют Бразилия, Аргентина и Канада. Россия производит порядка 2,9\% мирового объема сыра (рисунок. 1) [5].

Сыр является основным продуктом для молочной отрасли США. Среднегодовое потребление сыра на душу населения составляет 15 кг. Лидером в категории сыров является компания KraftHeinz, которой принадлежит 27\% рынка. Американские покупатели отдают предпочтения сырам, произведенным в ремесленных сыроварнях, а не в крупных транснациональных компаниях.

Одним из главных поставщиков сыра на мировые рынки является Франция, осуществляющая производство 400 видов сыров. Кроме того, к странам-сыроделам, которые ежегодно увеличивают продажи сырной продукции, можно отнести Австрию, Швейцарию, Голландию, Англию и Испанию.

В России насчитывается более 500 предприятий, производящих твердые и жирные сыры, и около 200 предприятий - плавленые сыры. Основные крупные предприятия сосредоточены в Центральном, Центрально-Черноземном, Поволжском и Уральском регионах [7, 8, 9].

Среди крупнейших производителей твердых и мягких сыров можно выделить компании ТНВ «Сыр Стародубский» (Брянская область), «Можгасыр» (Удмуртия), сыр- комбинат «Калининский» (Краснодарский край), «Вамин Татарстан» (Татарстан). Крупнейшими производителями плавленых сыров являются «Хохланд Руссланд» (Московская область), «Валио» (Москва и Московская область), ОАО «Московский завод плавленых сыров «Карат», ЗАО «Янтарь» (Воронежская область) и «РостАгроКомплекс» (Мо-

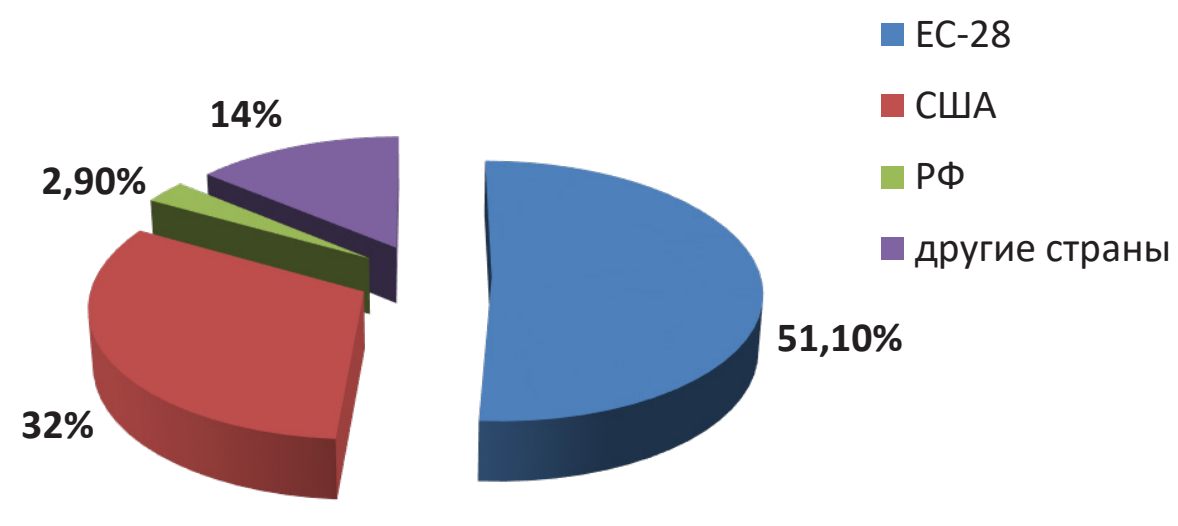

Рисунок 1. Структура мирового производства сыров по странам, в\% [6]

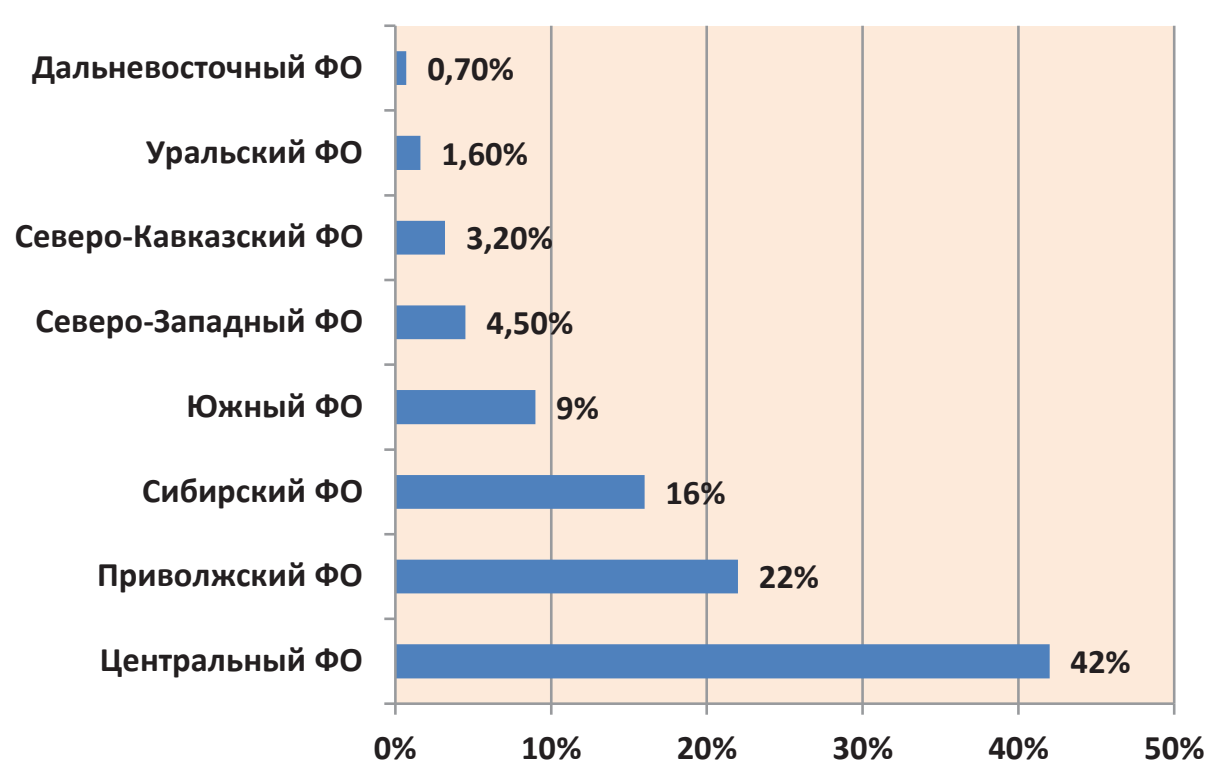

Рисунок 2. Структура производства сыров по Федеральным округам РФ за 2018 г.,\% 
сковская область) [10].

Российский рынок сыра является наиболее показательным по эффекту импортозамещения. По данным ИКАР, в 2016 году физическая емкость рынка составила 790 тыс. тонн, то есть на 5\% меньше, чем в 2013 году (840 тыс.тонн). До введения эмбарго доля импортных сыров в общем объеме потребления составляла 50\%: например, в 2013 году в Россию было ввезено 412 тыс.тонн сыра. В 2018 году поставки составили 187,8 тыс. тонн. В 2018 году доминирующее положение среди стран-поставщиков сыра в Россию заняла Беларусь, доля которой в российском импорте составила $87,2 \%$.

Объем производства сыров в 2018 году составил 473 тыс.тонн, что больше по сравнению с 2015 годом на 20 тыс.тонн или на 4,4\%. Драйвером роста производства сыров явился временный запрет на импорт молочной продукции из стран ЕС, США, Австралии, Норвегии и Канады. Причиной увеличения объемов производства сыров в России послужил запрет на ввоз ряда продуктов из стран ЕС, США, Австралии, Норвегии и Канады [10, 11].

В 2018 году экспорт сыра из Российской Федерации составил 24,8 тыс. тонн на сумму 68,3 миллиона долларов, что составляет около 28\% экспорта всей молочной продукции. Основными рынками сбыта являются страны: Казахстан, Белоруссия, Украина, Киргизия, Азербайджан, Грузия и Монголия. Небольшие объемы российского сыра реализуются в дальнее зарубежье - США и Германию. В дальнейшем планируется расширять поставки в страны дальнего зарубежья, в частности, в Китай.Чили стало крупнейшим экспортером сыра в Россию в 2019 году.

По состоянию на 2017 год мировой рынок сыров составил 30,4 млрд. \$ Ведущие экспортеры сыра - страны ЕС. Лидирующие позиции занимают Германия $(\$ 4,4$ млрд) и Голландия $(\$ 4,1$ млрд.). Важно, что в 2017 году данные страны значительно увеличили экспорт - на 20\%-22\%. Кроме стран Европы, значимую роль в мировой торговле сырами играют США и Новая Зеландия. Их объем экспорта в 2017 году также существенно вырос (на $15 \%-20 \%)$ и составляет около \$1,4 для каждой из стран. В 2017 году Россия находится на 10 месте в мире по импорту сыров (в денежном выражении).

Поскольку производство сыра является очень «молокоемким»: из 10 кг молока производится 1 кг сыра. Поэтому производство сыров преимущественно сосредоточено в 20-22 регионах страны - тех, которые лучше других обеспечены сырьем. В частности, выпуск сыра налажен в Вологодской области, Алтайском крае, Башкирии, Удмуртии и других. Низкая товарность производства молока не позволяет нараститьпроизводство молочной продукции: из 31,7 млн.т произведенного в 2017 г. сырого молока на переработку направлено только около 20,3 млн.т [12].

Согласно приказу МинздраваРоссии от 10.08.2016 г. № 614 «Об утверждении Рекомендаций по рациональным нормам потребления пищевых продуктов, отвечающих современным требованиям здорового питания», рациональная норма потребления сыра на человека в год составляет 7 кг. Лидеры по мировому потреблению сыра являются Франция, Финляндия, Германия, Греция и Люксембург.

Наибольшую часть отечественного рынка занимают твердые сыры (65\%). На втором месте сырные продукты с долей 22,7\%. Согласно ГОСТу, сырный продукт изготавливается по технологии производства сыра, но является молокосодержащим (не менее 20\%), а не молочным изделием. При производстве допускается использование кокосового и пальмового масел, а также немолочных белков и других консервантов. На долю полутвердых и плавленых сыров приходится, соответственно, $21,1 \%$ и 17,1\% производства. 11\% приходится на мягкие и кисломолочные сыры. Таким образом, российские потребители отдают предпочтение твердым сырам [14].

Таблица 3. Производство, импорт и экспорт сыров в России

\begin{tabular}{|c|c|c|c|c|c|}
\hline Годы & $\begin{array}{c}\text { Производство } \\
\text { сыров, тыс.т }\end{array}$ & Импорт, тыс.т. & Экспорт, тыс.т & $\begin{array}{c}\text { Ёмкость рынка } \\
\text { (тыс.т) }\end{array}$ & $\begin{array}{c}\text { Емкость рынка } \\
\text { (млн.дол) }\end{array}$ \\
\hline 2015 г. & 453 & 208 & 12 & 649 & - \\
\hline 2016 г. & 459 & 204,2 & 12 & 790 & - \\
\hline 2017 г. & 464 & 206,4 & 12 & - & - \\
\hline 2018 г. & 473 & 187,8 & 24,8 & - & 68,3 \\
\hline
\end{tabular}




\section{Потребление сыра , кг/год (2018 г.)}

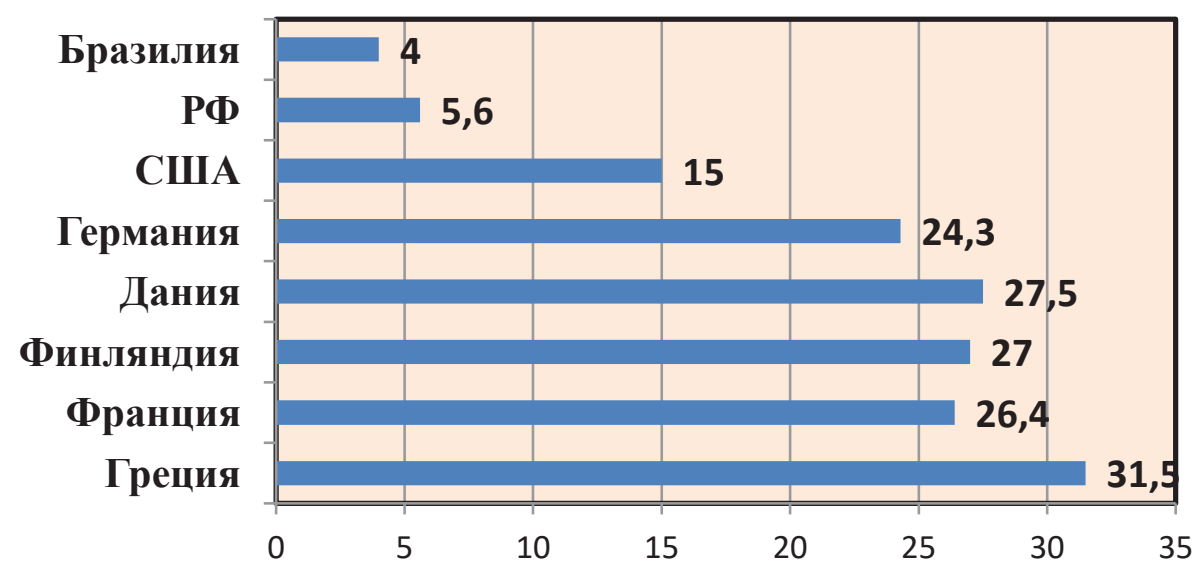

Рисунок 3. Потребление сыров в РФ и в других странах-лидерах за период 2018 г., кг.

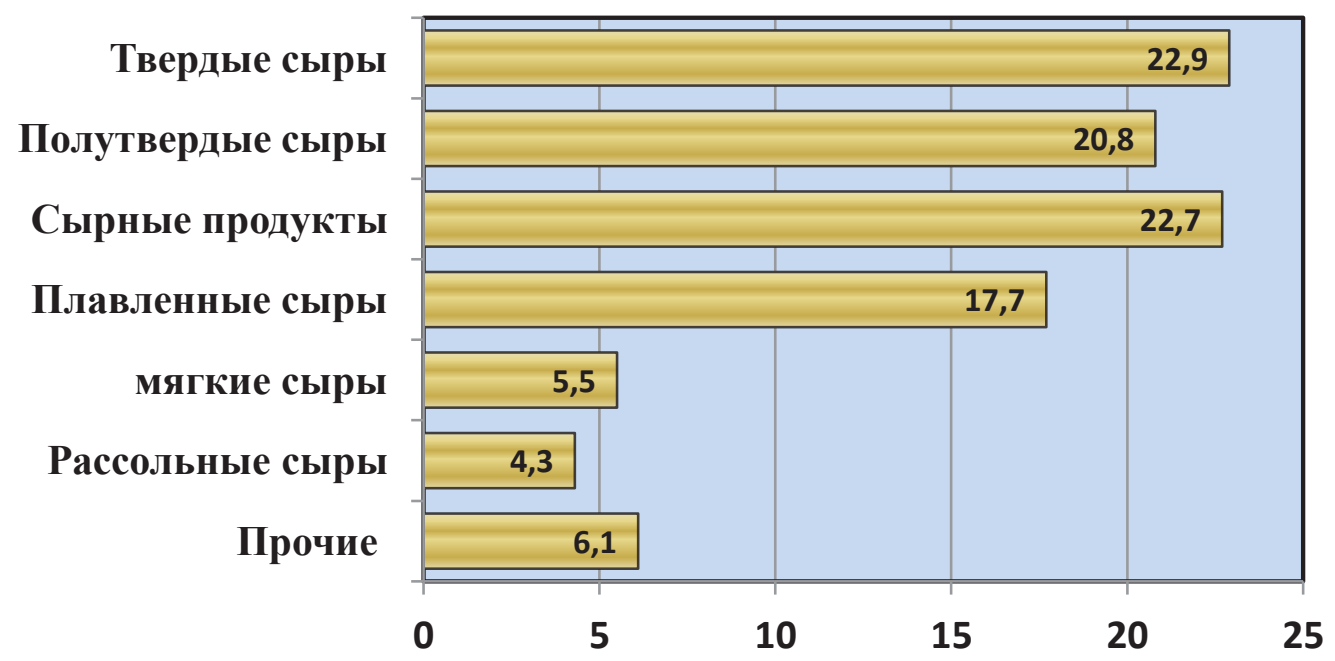

Рисунок 4. Структура производства сыра по видам в РФ в 2018 г., в\% [15,16]

Таблица 4. Динамика производства различных видов сыров России, тыс.т

\begin{tabular}{|l|c|c|c|c|}
\hline \multicolumn{1}{|c|}{ Виды сыров } & 2015 г. & 2016 г. & 2017 г. & 2018 г. \\
\hline - твердые & 144 & $137(22,9)$ & 141,7 & 153,2 \\
\hline - полутвердые & 113 & $125(20,8)$ & 129,4 & 38,9 \\
\hline - мягкие & 28 & $33(5,5)$ & 35,1 & 26,7 \\
\hline - рассольные & 24 & 22 & 24,6 & 118 \\
\hline - плавленые & 103 & $106(17,7)$ & 105 & 9,9 \\
\hline - копченые & 13 & 14 & 9,3 & 21,3 \\
\hline - другие сыры & 18,6 & 19,1 & 19,7 & 162,5 \\
\hline - сырные продукты & 145 & $149(22,7)$ & 150 & \\
\hline
\end{tabular}


Следует сказать, что в классификации сыров имеются разночтения.

Так, в классификации технологов - сыроделов к твёрдым видам сыров относятся сыры, имеющие весьма низкий уровень влаги в сыре (менее 30\%). При этом, практически все сыры, выпускаемые в России, относятся к группе полутвердых сыров. По этой классификации только очень небольшая группа сыров (типа «Пармезан») относится к твердым.

В настоящее время в РФ имеется рейтинг лучших сортов российского сыра (рейтинг составлен по количеству запросов в поисковых системах):

1 место - сыр «Российский»;

2 место - сыр «Голландский»;

3 место - сыр «Дор Блю» и «Гауда».

Признавая необходимость резкого увеличения производства сыров при минимальных капитальных затратах и экономном расходовании сырья, необходимо выделить следующие направления развития сыродельной отрасли:

- пересмотр ассортимента вырабатываемых сыров. Упорядочение ассортимента сыров, совершенствование их видовой структуры в настоящее время актуально и может обеспечить выпуск сыров с большим выходом, увеличить объем валовой продукции, получить высокую рентабельность производства;

- развитие производства мягких сыров.Высокая рентабельность мягких сыров является залогом того, что при правильной организации производства и сбыта, удельный вес их в общем объеме натуральных сыров будет постоянно возрастать, а большой их вкусовой диапазон удовлетворять потребности отечественного потребителя;

- создание и внедрение интенсивных технологий твердых сыров;

- развитие производства и создание конкурентоспособных технологий плавленых сыров;

- организация производства комбинированных сыров;

- организация массовой переработки сыворотки;

- развитие производства и создание технологий сыров с лечебно-профилактическими свойствами;

- улучшение качественных показателей сыров;

- использование в сыроделии новых техно- логических процессов;

- повышение роли влияния вузовской и отраслевой науки на развитие сыродельной промышленности [14].

На формирование структуры рынка сыров и их ассортимента влияет несколько факторов. Важными являются покупательная способность населения. Снижение покупательной способности вынуждает производителей применять способы удешевления себестоимости сыров. Этим вызван рост сырных продуктов, в которых молочный жир заменен на растительный. Прибегают к применению недостаточно качественных ингредиентов при выработке сыров (молокосвертывающие ферменты, бактериальные препараты и закваски), что снижает качество сыра и его востребованность покупателем.

Вторым фактором является высокий уровень кредитных ставок банков.

При отсутствии собственных оборотных средств, предприятия вынуждены кредитоваться. При этом за весь период созревания и реализации сыров, нарастает сумма платежа. Срок созревания элитных сыров (швейцарского, советского и др.) достигает нескольких месяцев, это увеличивает себестоимость сыра. В свою очередь, это сказывается на конечной цене продукта и сокращении объемов реализации.

Третьей причиной является недостаток сырья для производства сыров. Это ведет к конкурентной борьбе за молоко-сырье и, соответственно к росту цены на него. Немалую долю в росте себестоимости играет и рост потребляемых энергоресурсов.

Развитие мелких, частных сыроварен не даст серьёзного роста объемов производства сыра. Несмотря на развивающееся «импортозамещение» производством различных видов сыра, расширение их ассортимента, это лишь незначительно увеличит их производство на душу населения. Примером может служить Франция, в которой вырабатывают тысячу наименований сыров, но более 90\% объемов вырабатывают на крупных предприятиях, перерабатывающих сотни и тысячи тонн молока в сутки.

Поэтому первоочередными задачами, стоящими перед администрациями, сельским хозяйством и молокоперерабатывающей отраслью, являются рост объемов производства молока и корректировка кредитной политики 


\section{Библиографический список}

1. [Электронный ресурс] https://sfera.fm/articles/molochnaya/mirovoi-rynok-moloka-i-molochnykh-produktov_ 1546

2. [Электронный ресурс] https://sibac.info/shcoolconf/natur/vi/32301

3. [Электронный ресурс] https://agrarii.com/v-rossii-v-2018-godu-uvelichilos-proizvodstvo-syra/

4. [Электронный ресурс] https://www.agroxxi.ru/stati/8-krupneishih-ferm-mira.html]

5. [Электронный ресурс] http://ikc.belapk.ru/upload/iblock/48d/48dc63e8ab2eeda873ef65a2a9f0e492.pdf

6. [Электронный ресурс] http://www.globalreach.ru/publications/mirovoy-rynok-syra.html

7. [Электронный ресурс] https://marketing.rbc.ru/articles/10236/

8. [Электронный ресурс] https://milknews.ru/index/RF-proizvodstvo-syr.html

9. [Электронный ресурс] https://www.agroxxi.ru/analiz-rynka-selskohozjaistvennyh-tovarov/top-regionovproizvoditelei-syra-i-syrnoi-produkcii-v-rossii-v-2019-godu.html

10. [Электронный ресурс] https://www.dairynews.ru/news/

11. [Электронный ресурс] https://produkt.by/news/evrosoyuz-osnovnye-cifry-i-igroki-molochnogo-rynka-chast-ii

12. Рынок сыра в России: исследование и прогноз до 2023 г. [Электронный ресурс] Выпуск: ноябрь, 2019 г. https://roif-expert.ru/food/molochnye-produkty/rynok-syra.html

13. [Электронный ресурс] http://milklife.by/klassifikatsiya-syirov/

14. [Электронный ресурс] https://roif-expert.ru/food/molochnye-produkty/rynok-syra.html

15. [Электронный ресурс] https://finance.rambler.ru/markets/41815323-obem-proizvodstva-syrov-v-rf-za-2018-guvelichilsya-na-2-5/

16. [Электронный ресурс] http://foodmarket.spb.ru/current?article=2611 